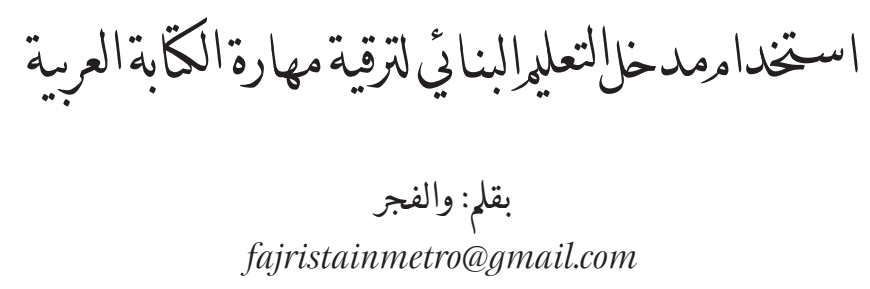

\begin{abstract}
The Arabic writing skill is one of the important Arabic language skill and it is a main goal of the Arabic learning as foreign language. However, it does not get a main concern in Arabic teaching as foreign language. Beside, the students' Arabic writing skill is still in low level. This research aims to increase students' Arabic writing skill through the constructive teaching approach and to describe the effective teaching method of Arabic writing skill as foreign language. This research used the classroom action research method conducted in two cycles. Each cycle consists of four steps they are: 1) planning, 2) action, 3) observation, and 4) reflection. The data of research consist of teaching and learning process of Arabic writing skill in classroom and students' Arabic compositions. The research participants are a lecture and 30 students of Arabic writing skill. The results of research showed that the Arabic writing skill teaching through the constructive approach consists of three phases they are: 1) pre writing phase, 2) writing phase, and 3) post writing phase. The results also showed that the constructive teaching approach is effective to increase students' Arabic writing skill.
\end{abstract}

مقدّمة مقة

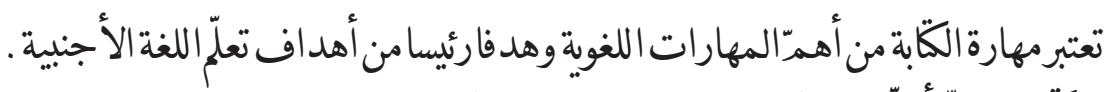

ومهارة الكّابةلا تقلّ أهميّة عن الكلا مـوالقراءة. فإذاكان الكلا مدمسيلة من وسائل اتصال الإنسان

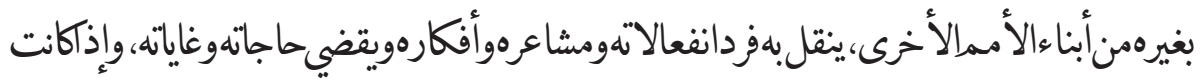


القراءة أداة الإنسان في الترحال عبر المسافات البعيدةوالأزمنة العابرة والثقافات المختلفة، فإن إنان

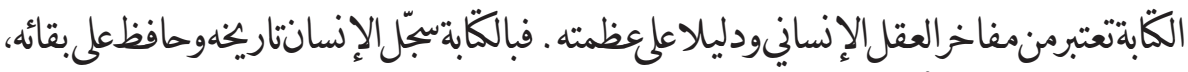

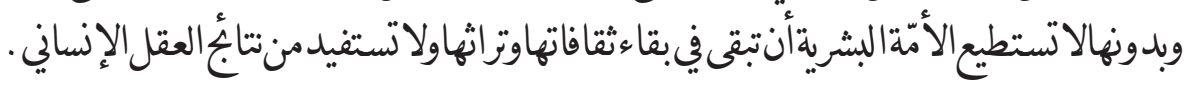
وإذكانت للغةتفياة الإنسانوظيفتانرئيستانهماوظيفة|تصاليةووظيفةتسهيلئليةا لتفكير

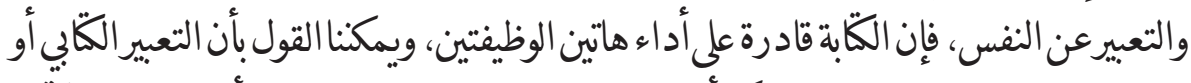

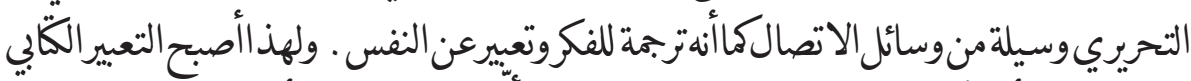

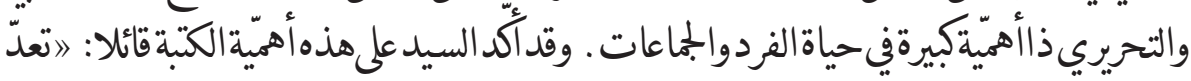

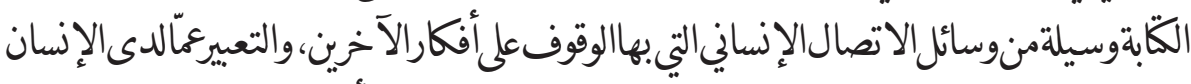

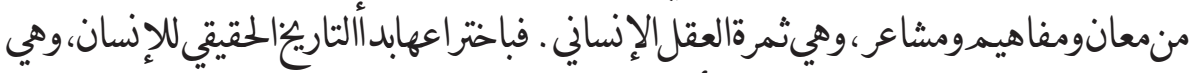
التئخلدت الحضارات البشرية علىمرّالأزمانه . '.

وإنكانت الكَبة مهمّةكوسيلة منوسائل الاتصال والتعبيرعن النفسووالفكر، فإنهامهمّة أيضا

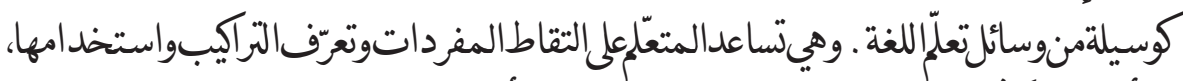

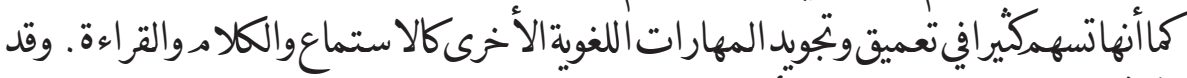

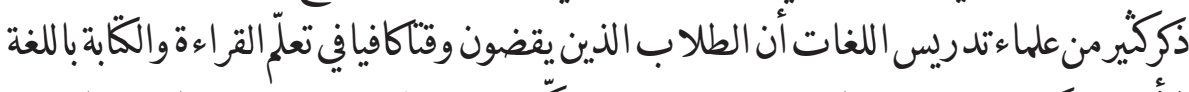

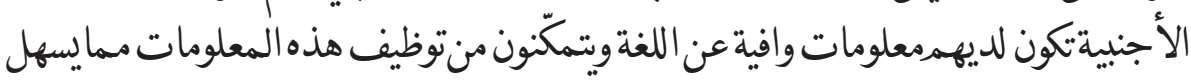
عليهماستخدامراللغة|ستخداماصحيحا.

ومع أهميّة الكّةكَكهارة لغويةوكوسيلة من وسائل التعلمّوأداة من أدوات الإنسان في الاتصال

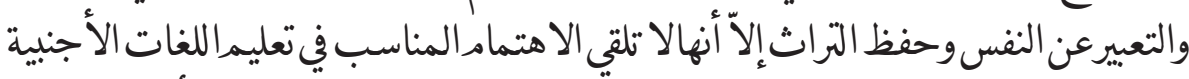

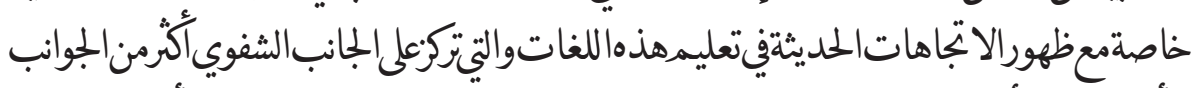

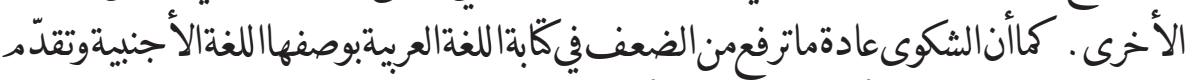

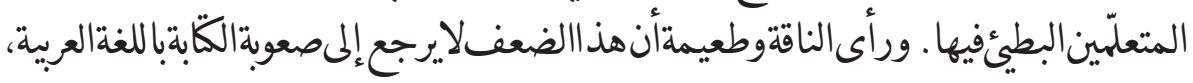

محمود أحمد السيد، في طرائقتدريس اللغة العربية، (دمشق: منشورات جامعة جمش، 1997)، ط. r، ص. 
والفجر : استخدامدمدل التعليمالبنائي لترقية مهارةالكتبة العربية

وإنمايرجع إلى قصور في طرق التدريس وفي البراجح المعدّة لتدريس الكّبةوعده الإعداد الكافي

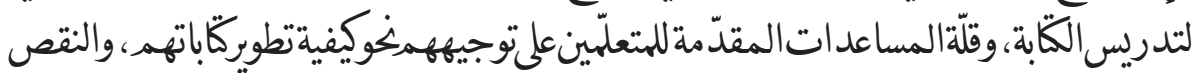

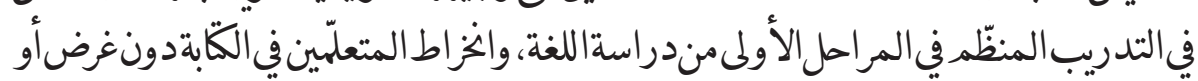
هدف أودوافع، وتقديموضوضوعات غيرمناسبة للكّابة. ؛

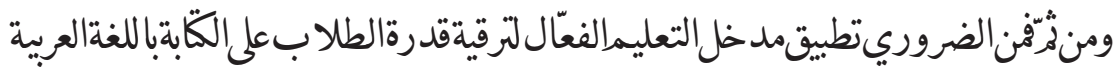

بوصفها اللغة الأجنية، وهومد خل يبجعلعملية تعليمدهارة الكّبة باللغة العربية حية وديناميكية

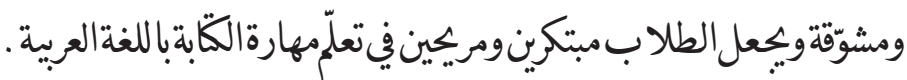

وانتلاقامنهنافإن البحث فيترقية مهارة الكّابةباللغة العبية بمد خل التعليمالبنّائي يعتبرأمرا

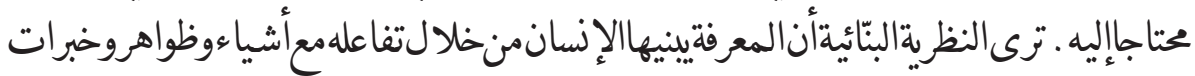

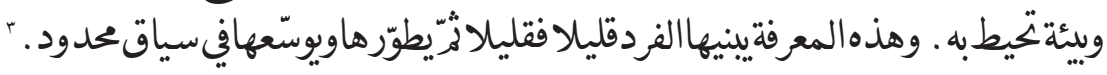

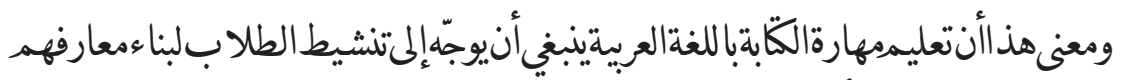

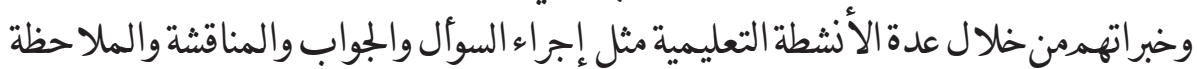

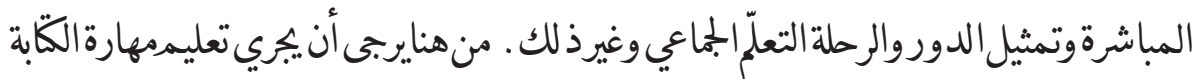

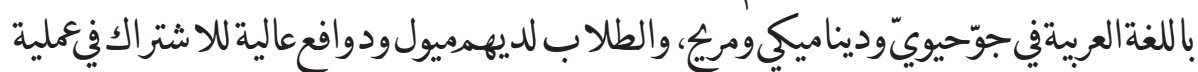

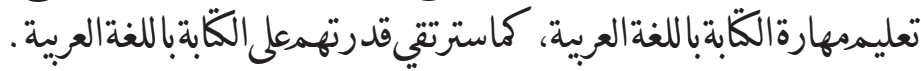

محمودكامل الناقة ورشدي أحمد طعيمة، طرائقتدريس اللغة العربية لغير الناطقين بها، (المغرب: منشورات

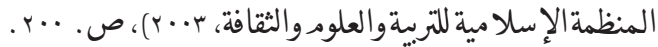

3 Paul Suparno, Filsafat Konstruktivisme dalam Pendidikan, (Yogyakarta: Kanisius, 1997), h. 28. 


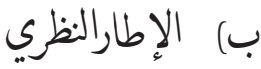

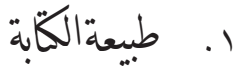

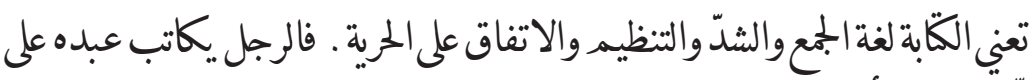
مال يؤديه منجّما، أي يتفت معه على حريته مقابل مبلغ من المال . وكماتعني الكّابة لغة القضاء

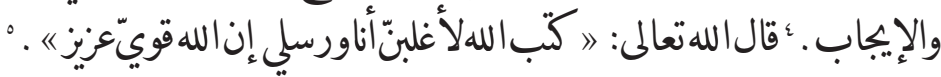

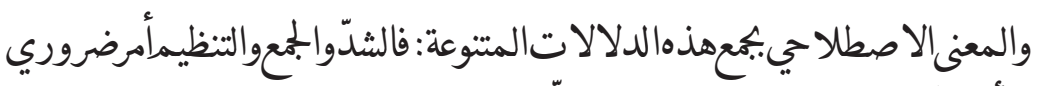

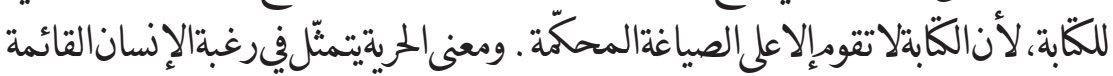

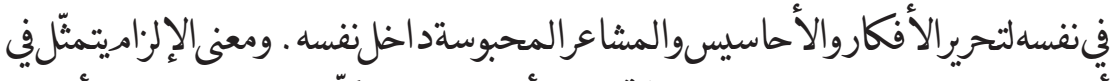

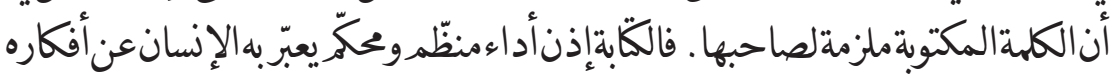

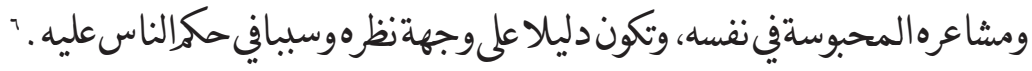

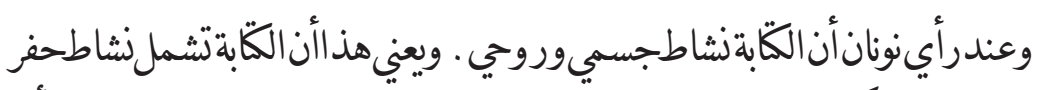

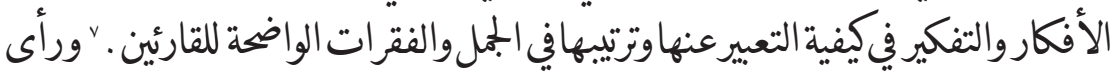

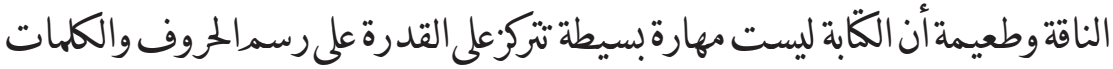

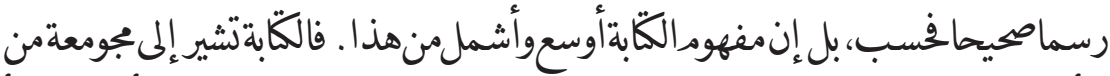

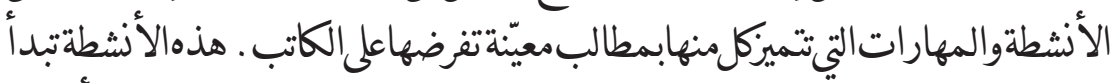

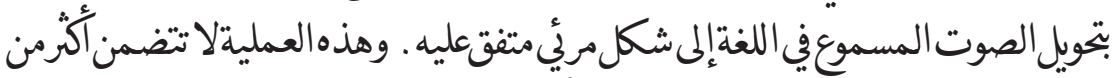

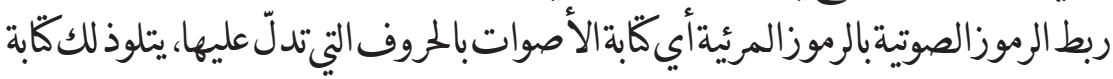

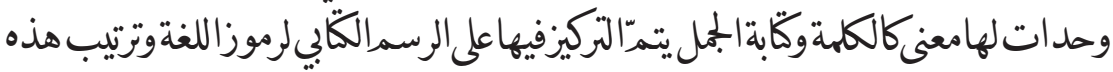

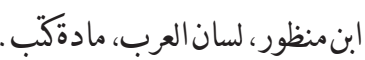

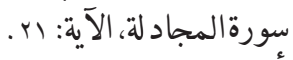

$$
\begin{aligned}
& \text { أحمد فؤادمحود عليان، المهارات اللغوية ماهيتها زطرائق تدريسها، (الرياض: دار المسلم للنشر والتوزيع، }
\end{aligned}
$$

7 David Nunan, Practical English Language Teaching, (New York: McGraw Hill, 2003), h. 88 . 
والفجر : استخد امدمدل التعليمالبنائي ترقية مهارةالكتبة العربة

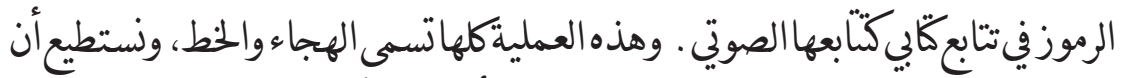

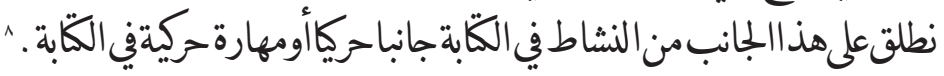

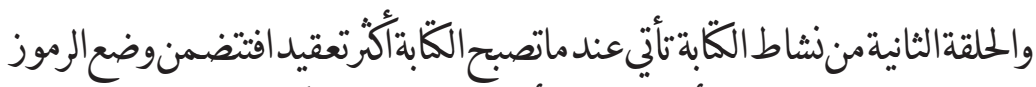

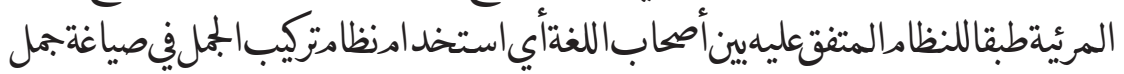

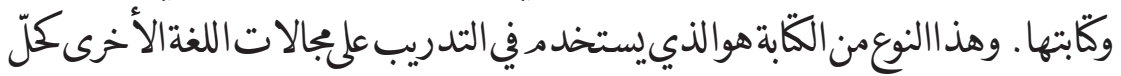

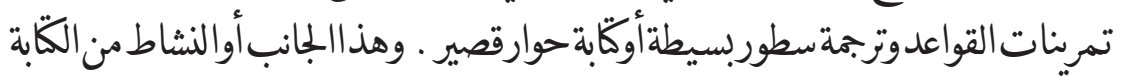

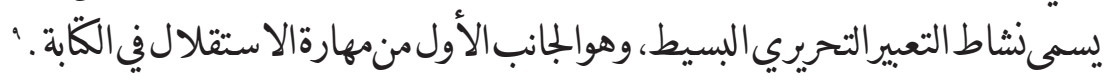
وبعدذلكتأتي مرحلة النشاط الكّابي المتطوّر ، وهي مرحلة التعبيرعن الأفكارفيشيكل

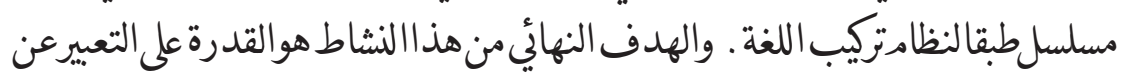

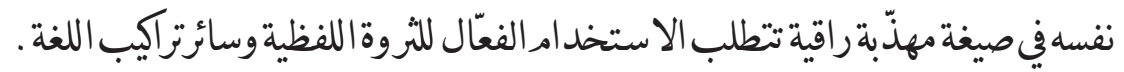

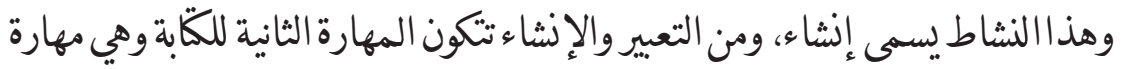

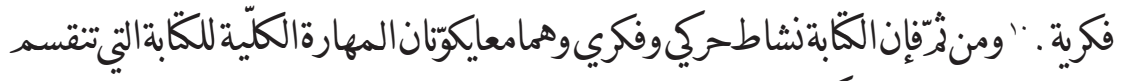
إلى مهارتين: مهارةحركةومهارةقفكية.

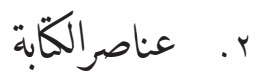

تتكون الكّابة من عناصرأساسيةفي الكلمةوالجملةوالفقرة. وكلعنصرمنهذهالعناصرله

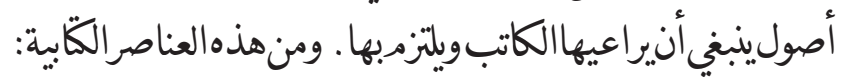

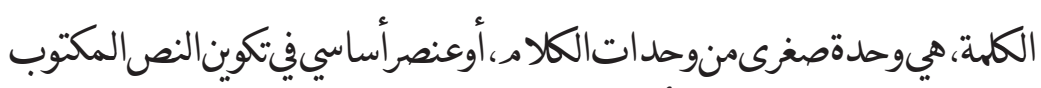
والمنطوق على يصوغنها الجمل والفقرات منها:

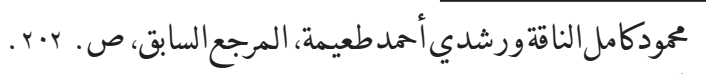

$$
\begin{aligned}
& \text { المرجع نفسه. } \\
& \text { المرجع نقفسه. }
\end{aligned}
$$

| النابة - An-Nâbighah, Volume 18 No.2 Tahun 2016 
- - معرفة المترادف والمشتركوالمتضات للكلمات، والحرصعلىأنيكوناختيار

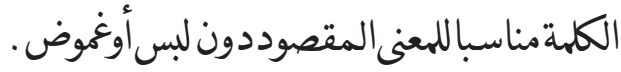
- مإدراك الدلالات المختلفة للكلمات.

- التمييز بين الكلمات الجيدة والكلمات الرديئة المبتذلة عند اختيار الكلماتهات. فعلى الكاتب أنيحسن اختيار اللفظ المناسب للمعنى والمقاه . - - إدراك الفرقبين المعرفةوالنكرة، والاسمدوالصفةقفي أداء المعنى المرادبه.

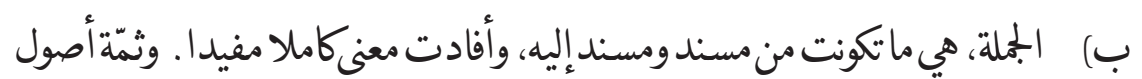

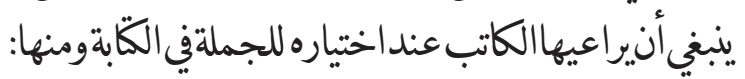
- مراعاةالالتزامبالقواعداللغوية للمكلمةداخل المجلة. - - مراعاة تناسب الجملة مع السياق طولا وقصرا، وتشيكلا أوتنظيما، وارتباطهابما قبلهاومابعد ها.

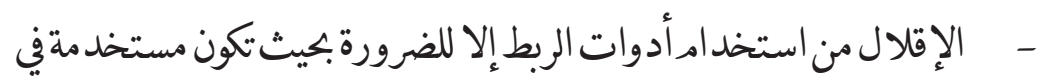
مانها الصحيح مع مراعاةدقةالمعنى . ج) الفقرة، هي جملة مترابطة تدورحول فكرةواحدةوتعالجهاتقصيلا وتطويرا. I 1 وهناك

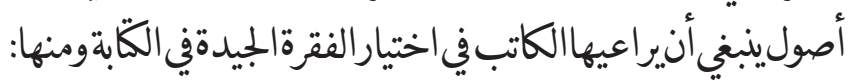
( ) الوحدة، ويقصدبوحدةالفقرةأنتدورجميعجملهاحولفكرةمركزيةواحدة. وتكون

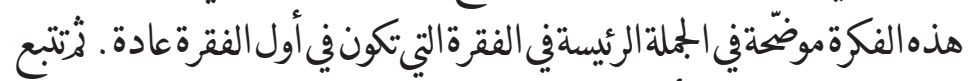

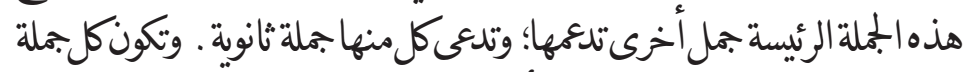

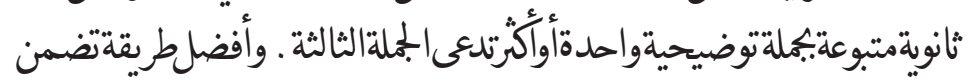

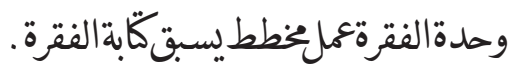


والفجر : استخدامدمدل التعليمالبنائي لترقيةمهارةالكّبة العربية

r ) التماسك، ويقصدبهأنترتبطجمل الفقرةبروابط لفظيةتدلّ علىنوعيةالعلاقات

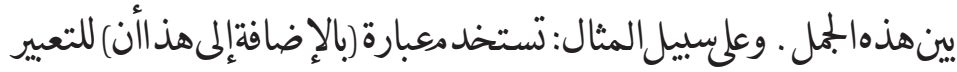

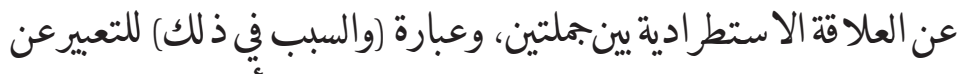

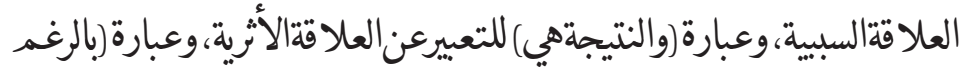

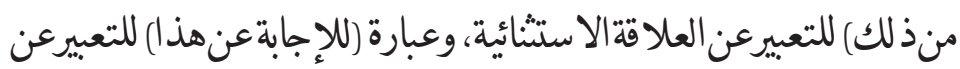

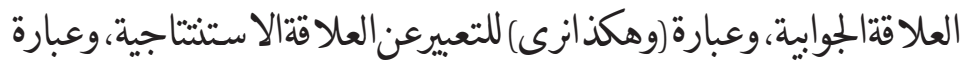

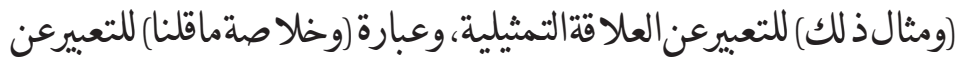

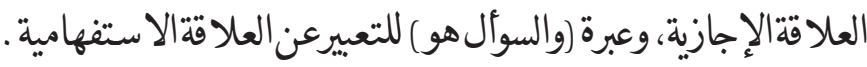

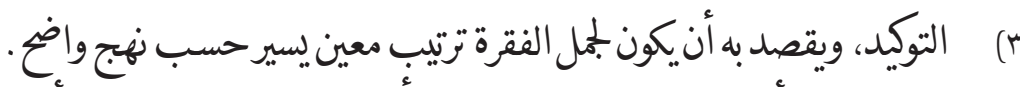

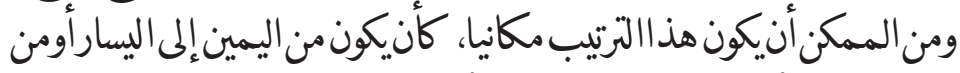

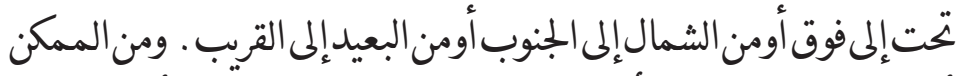

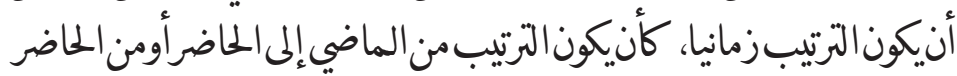

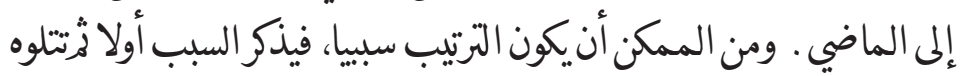

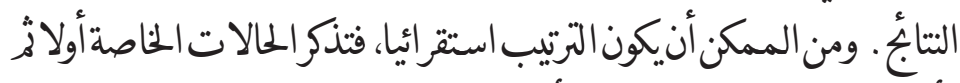

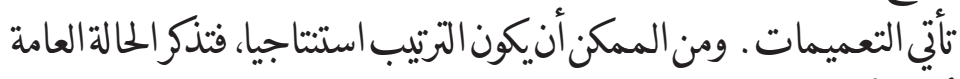
أولاثرثتأتي الحالات الفيمات. ودن الفردية.

الوضوح، وتحققوضوح الفقرةبتعريف المصطلحات الرئيسةوتجنبالتراكيب

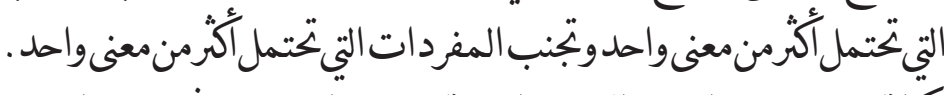

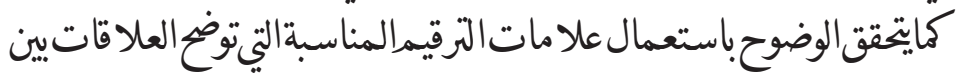

المبل.

0) الصحة، تتحقق صحة الفقرة عن طريق مراعاة أصول النحو والصرف واختيار

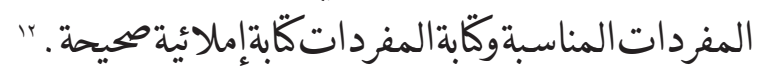

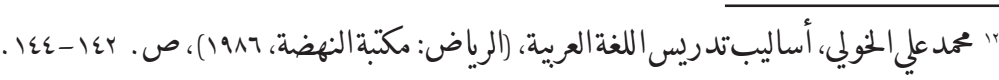


وبالإضافةإلىذلك، يرى المربّون أنثمة ثلاثة عناصرلا بد منتوافرهافي ميدان

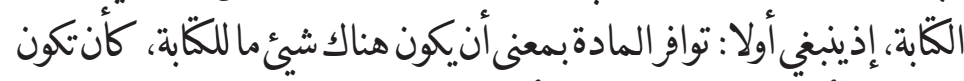

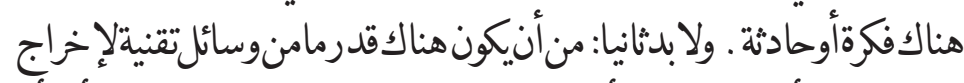

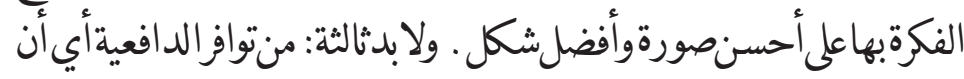

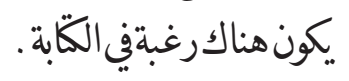

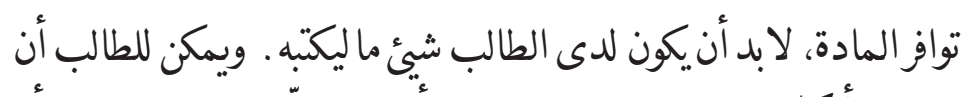

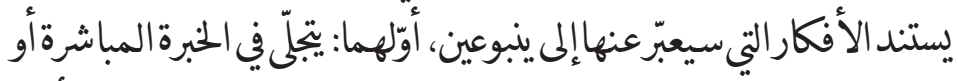

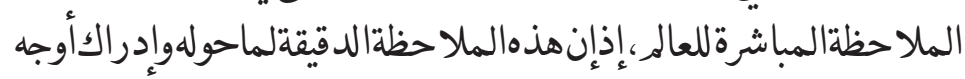

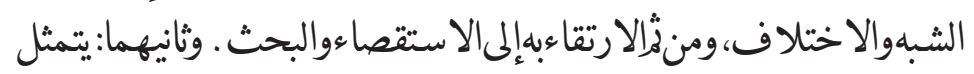

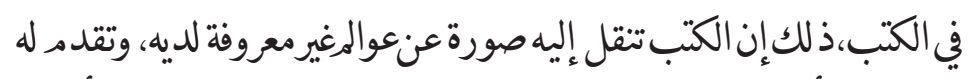

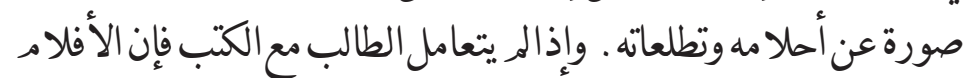

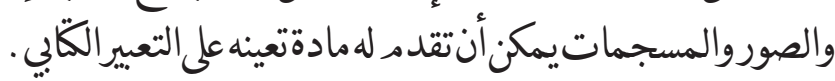

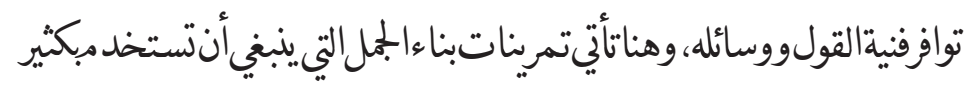

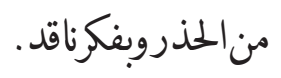

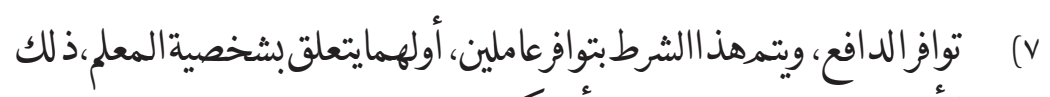

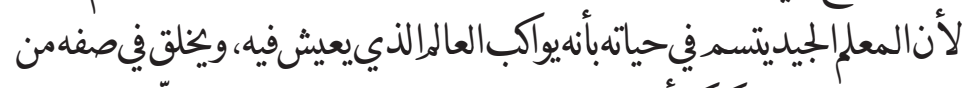

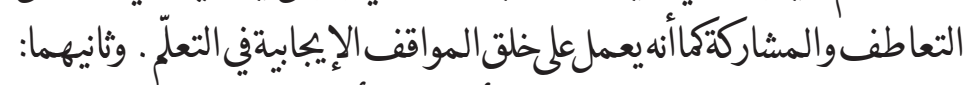

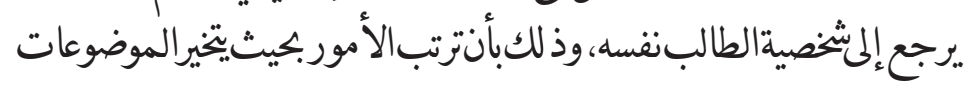

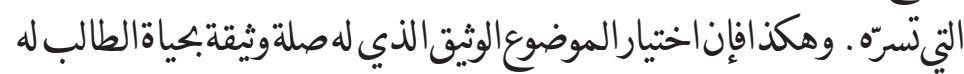

$$
\text { دوركيرفي استثارة الرغبة لديه. }
$$

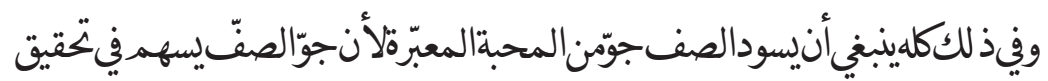
حيويةالفكر إذامارسها لمعلمبوعيفيكلفوصةتسنحله ـ وعلى المعلمأنيغني الخبرات المباشرة

$$
\text { " محمودأمدالسيد، في طرائتتدريس، ص. بوץ. }
$$


والفجر : استخد امدمدل التعليمالبنائي لترقية مهارةالكّبة العبية

عنطريتالزياراتوالمواقف الحية، والحبراتغيرالمباشرةعنطريتالقراءةوالأفلادوالصور

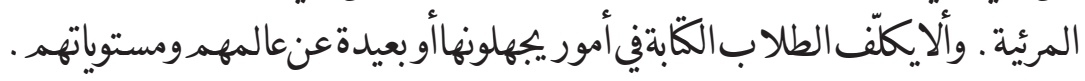

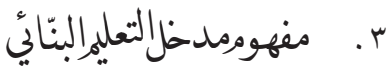

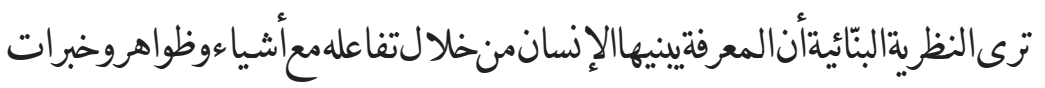

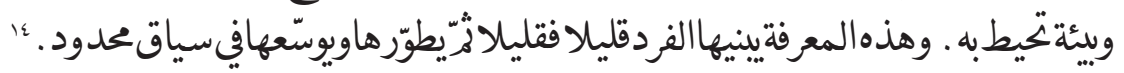

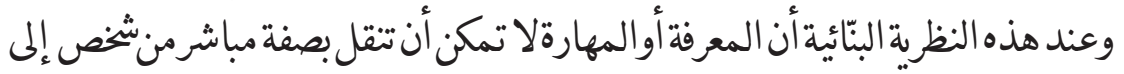

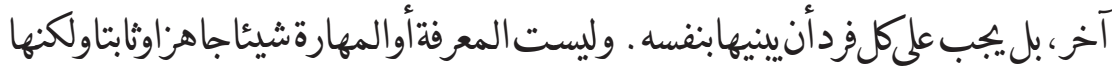

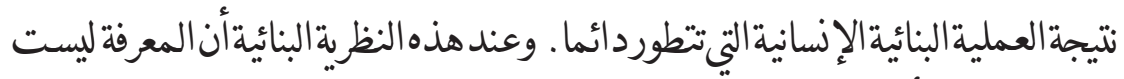

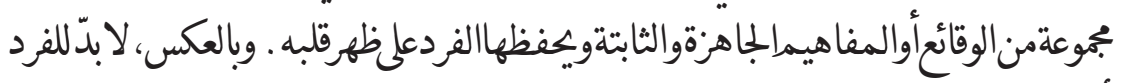

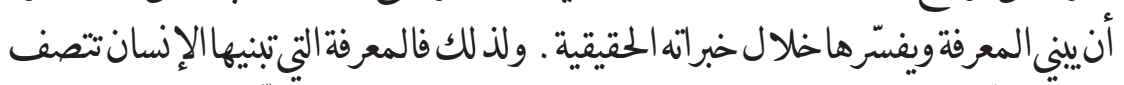

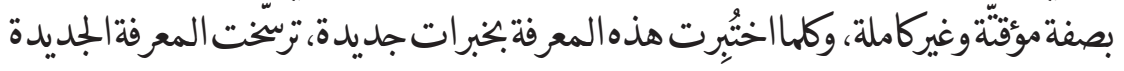
فيذهن الإنسان.

والإضافةإلىذلك، رأىكوكس أن الطفل بينيمعنى جديد افيبداية معرفتهم لأجلاعلية

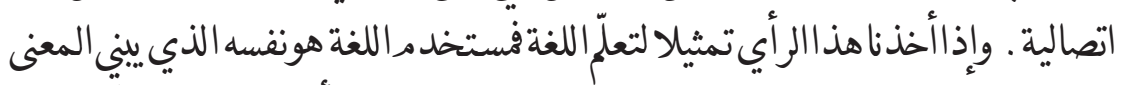

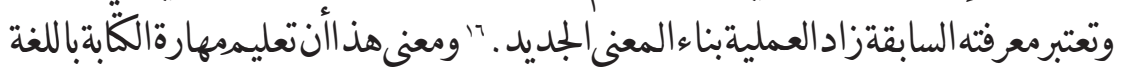

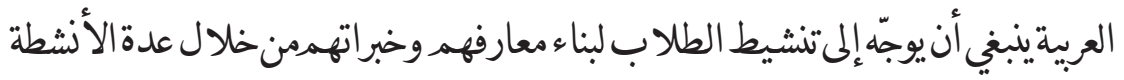

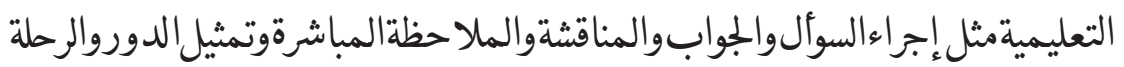
التعلّما المجاعي وغيرذلك.

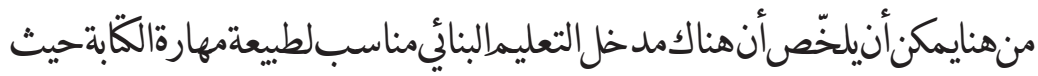

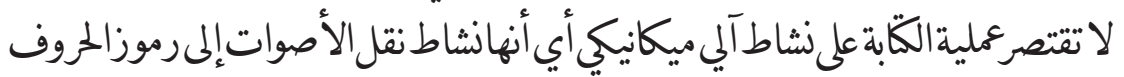

${ }^{14}$ Paul Suparno, Filsafat Konstruktivisme. h. 28.

${ }^{15}$ Nurhadi dkk., Pembelajaran Kontekstual dan Penerapannya dalam KBK, (Malang: Universitas Negeri Malang Press, 2004), h. 33.

${ }^{16}$ C. Cox, Teaching Language Arts, (Boston: Allyn \& Bacon, 1999), h. 40. 
أونقل الكلماتوالجملفحسب، بل إنهاؤسع وأشملمنذلك، فالكّابةنشاطبناء المعنى خلال

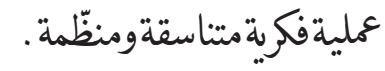

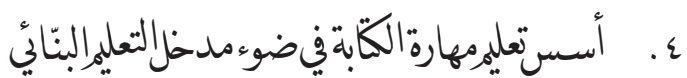

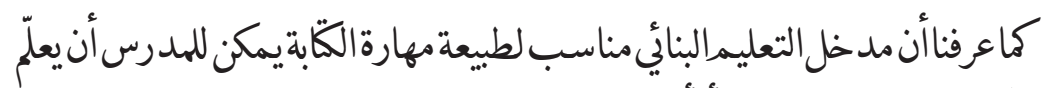

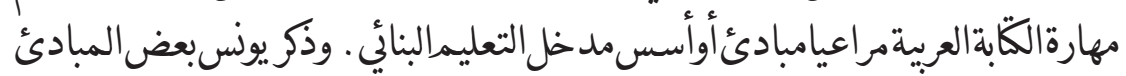

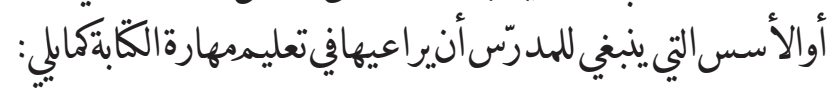

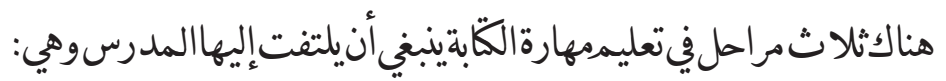

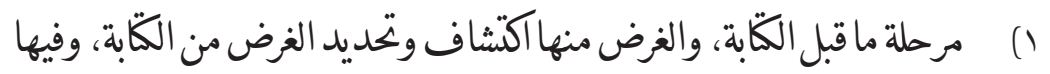

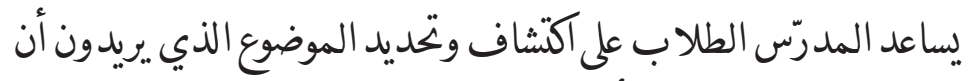

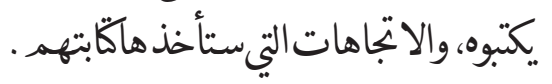

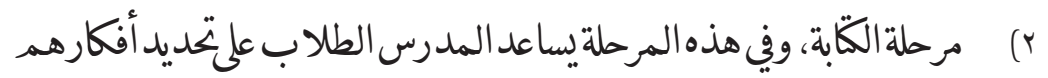

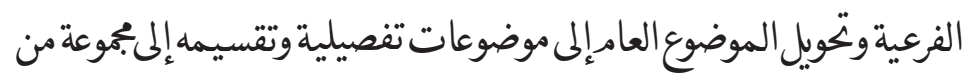

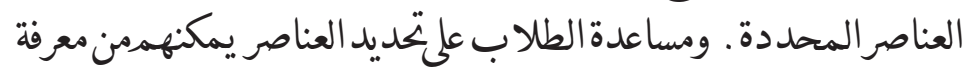

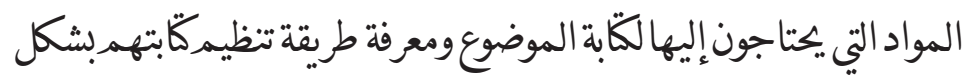
مناسب.

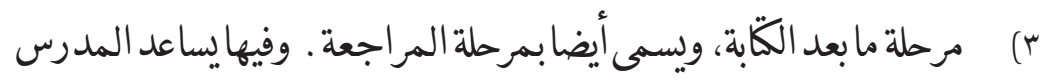

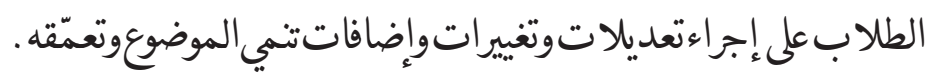

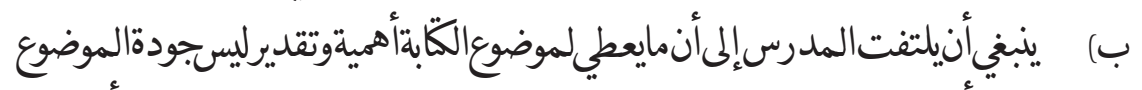

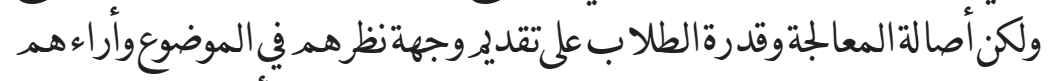

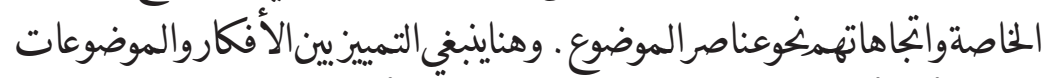

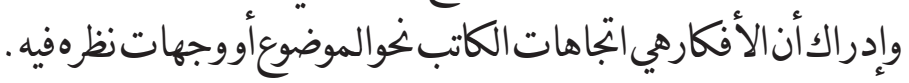


والفجر : استخدامدمدل التعليمالبنائي لترقيةمهارةالكّبة العربية

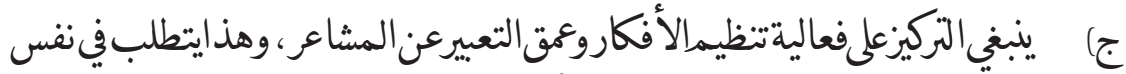

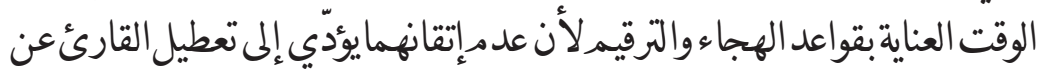

$$
\text { متابعةالأفكاروالمشاعرومعايشتها. }
$$

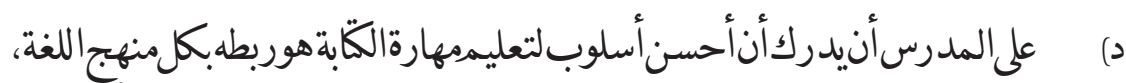

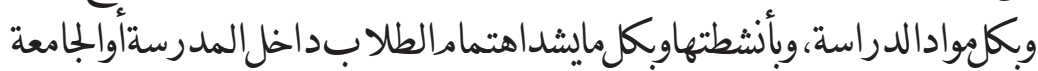

وخارجها.

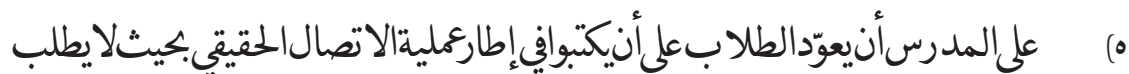

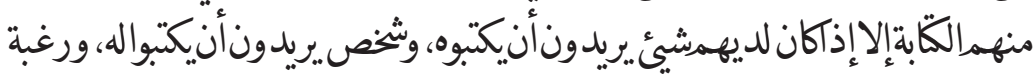

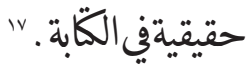

\section{ج) نهوجالبحث}

يهدف هذا البحث إلى ترقية مهارة الكّابة العبية بتطبيق مدخل التعليمالبنائي. وسيجري

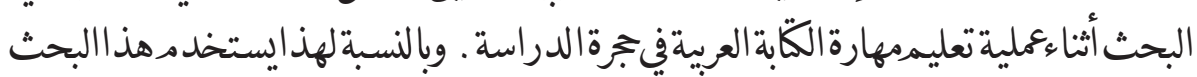

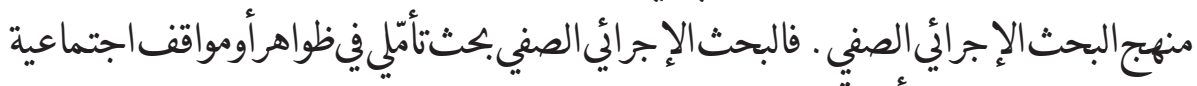

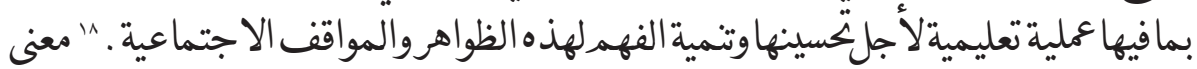

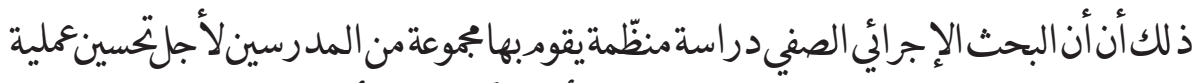

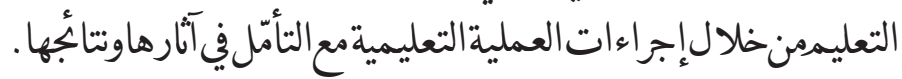

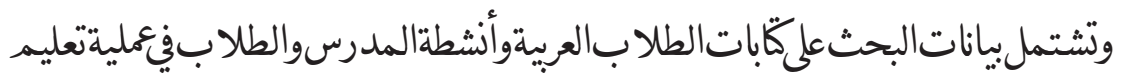

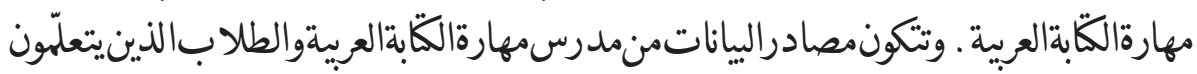

"ن فتي علي يونس وآخرون، أساسيات تعليما للغة العربةوالتربة الدينية، (القاهرة: دار الثقافة للطبعةوالنشر،

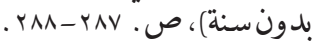

${ }^{18}$ Rochiati, Metode Penelitian Tindakan Kelas, (Bandung: Remaja Rosdakarya, 2005), h. 12 . 
مهارةالكّابة العربية الثانيةفي الفصل الدراسي الرابعيفقسمتعليما للغة العربيةلجامع جوراي سيوو

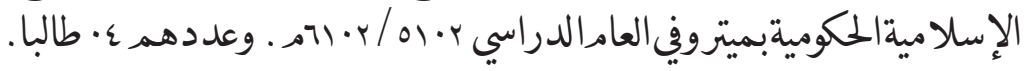

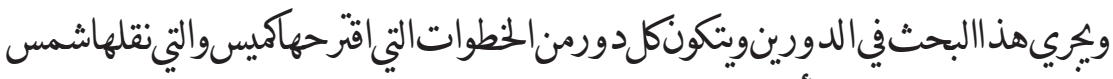

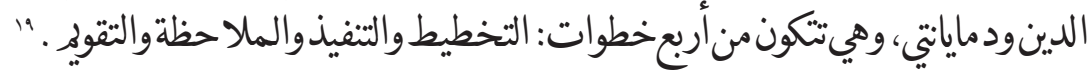

1. التخطيط

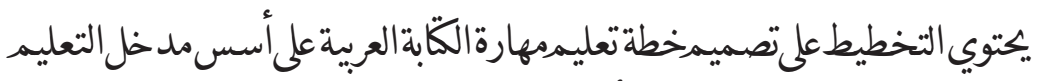

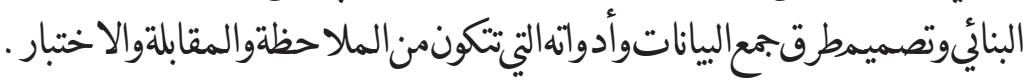

$$
\text { r. r التنفيذ }
$$

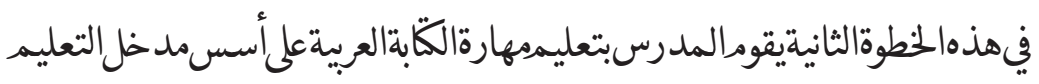

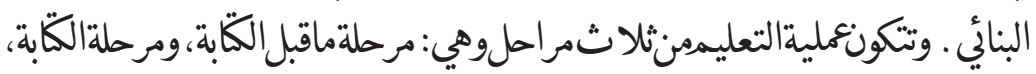

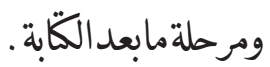

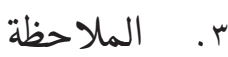

وفي هذه الخطوة الثالثة يلاحظ الباحثملية التعليم ويسجّل الأحداث والأشطة

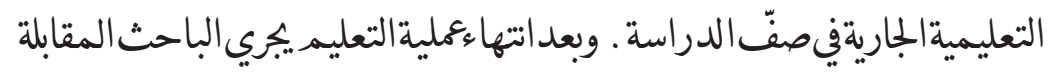

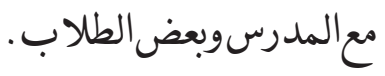
ع ـ ـ ـ التأمّل

بعدتفيذعلية التعليم والملاحظةوالمقابلةيقومالباحث بتحليل البيانات المحصولة

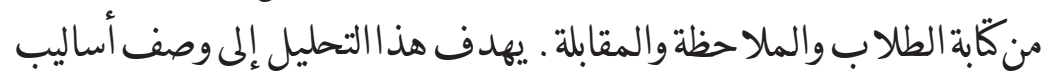

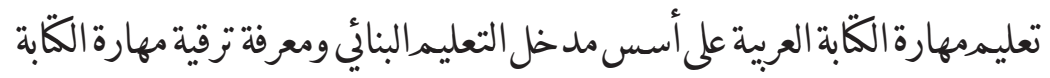
العربية، كمايهدف إلىوصف مزيامدخل التعليماليمالبنائئوعيوبها.

${ }^{19}$ Syamsuddin A.R. \& Vismaia S. Damaianti, Metode Penelitian Pendidikan Bahasa, (Bandung: Remaja Rosdakarya, 2006), h. 191. 
والفجر : استخدامدمدل التعليمالبنائي لترقية مهارةالكّبة العربية

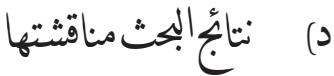

بناءعلىملا حظة ملية تعليمدهارةالكّابة العبيةفي الدورين، وجد الباحث أن المدرسقام

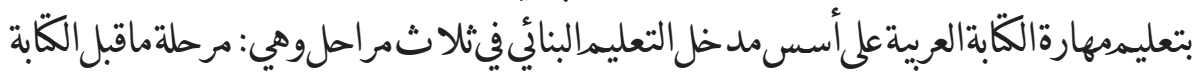

ومرحلة الكّابةومرحلة مابعدالكّبة.

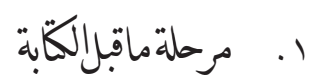

في هذه المرحلة الأولى من الكّابة، شرح المدرس أهداف التعليم والواجبات التي

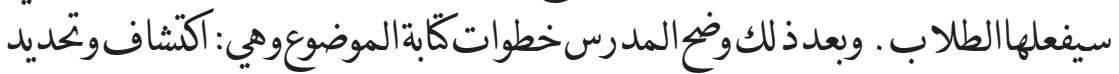

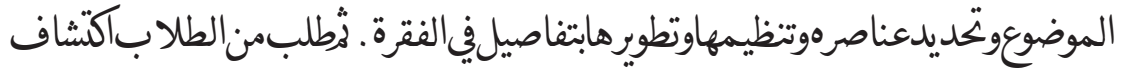

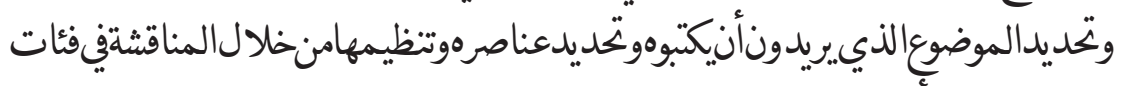

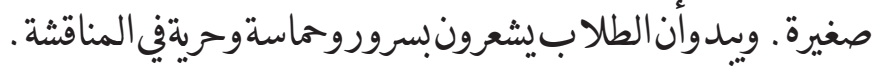

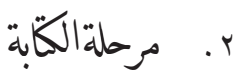

وفي هذها لمرحلةالثانيةمنالكّبة، طلب المدرسمنالطلابتسويرالموضوعوعناصره

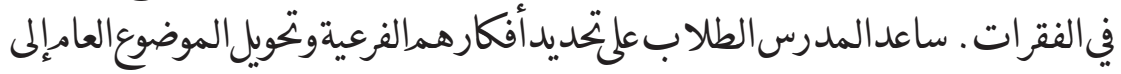

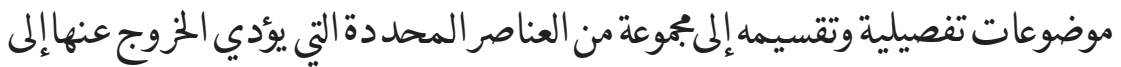

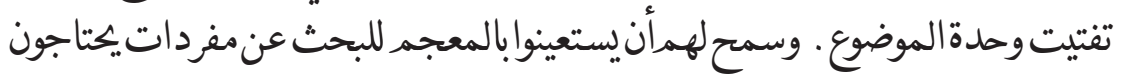

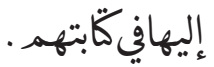

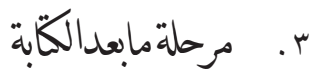

وفي هذه المرحلة الثالثة من الكّابة، طلب المدرس من الطلاب مراجعة كّاباتهم إبها

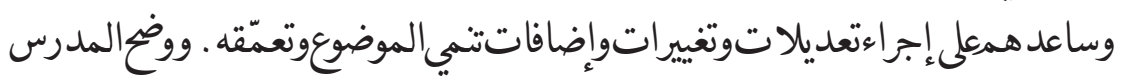

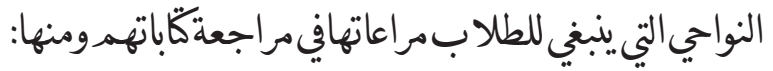


- مضمون الخّابة، وهو يحتوي على الأفكار التيتتدرجتحت الموضوع منحيث

مناسبتها للموضوعوسعةوصفهاودقتها.

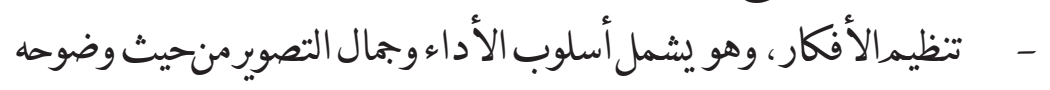
وترتيبهوربطهين الفقرات.

- - المفردات، وهيتحتوي علىاستيعابالمفرداتواستعمالالألفاظفي المعاني التي الموضعت لهات.

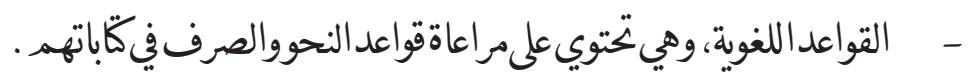

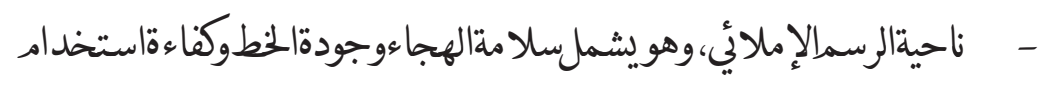
علامات الرقيم.

وبعدالمراجعةوالتعديلات، طلب المدرسمنبعضئ الطلاب أنيقرؤوآكاباتهمأماه

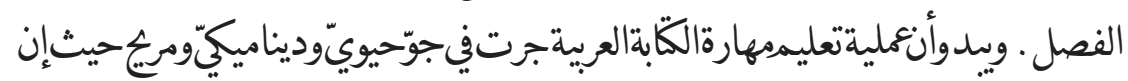

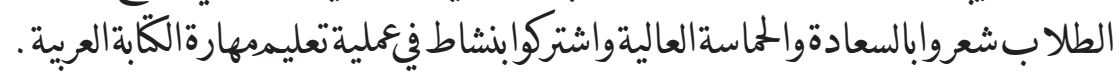

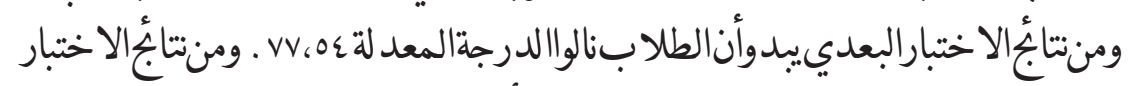

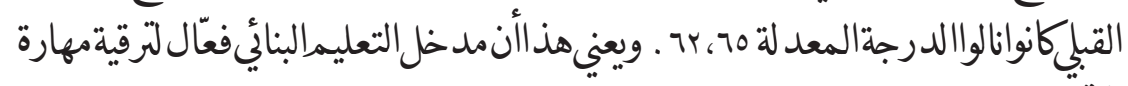

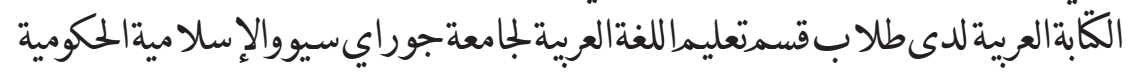

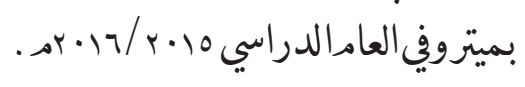

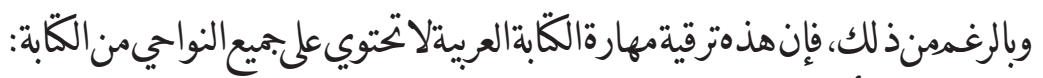

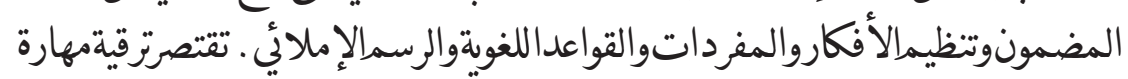

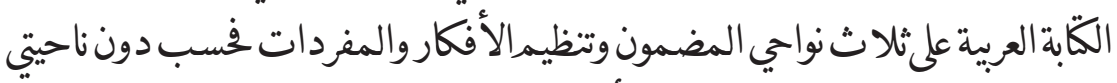

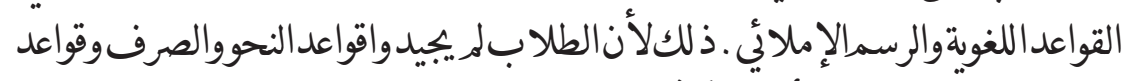

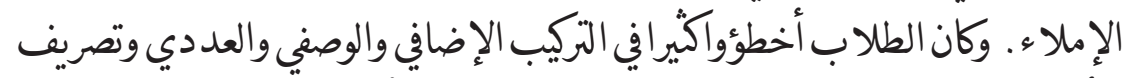

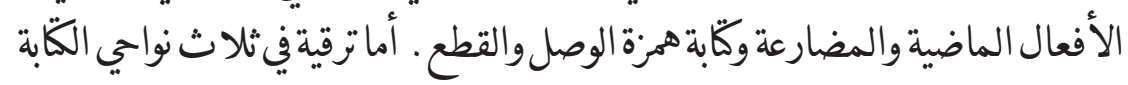


والفجر : استخدامدمدل التعليمالبنائي لترقيةمهارةالكّبة العربية

العربية فذلكلأن لهمفرصةًافية للتدريب على تحديد الموضوع وعناصرهوتنظيما الأفكارفي

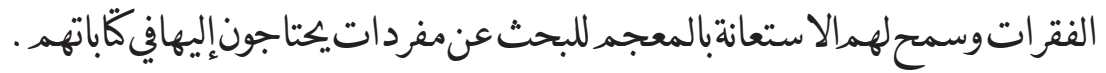
وعلىكلحال، فهذه ترقية مهارة الكّابة العربية تدلّ على أن مدخل التعليمالبنائي لايركز

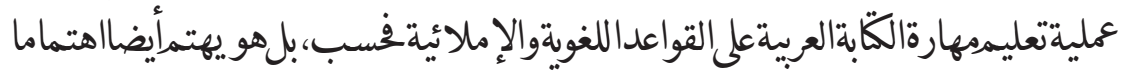

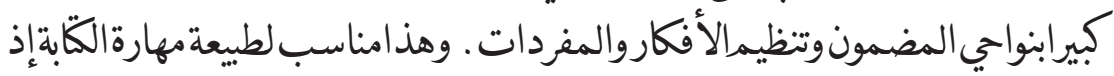

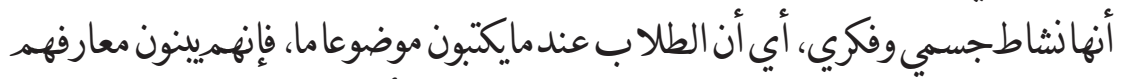

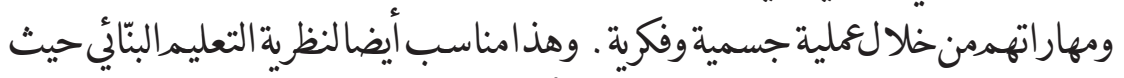

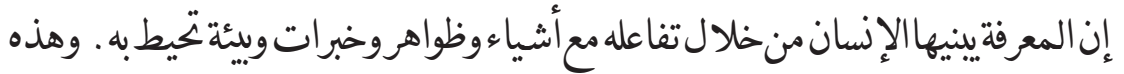

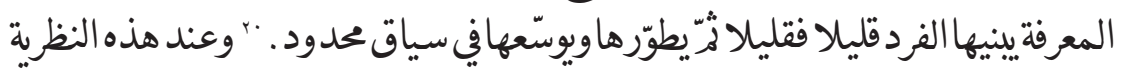

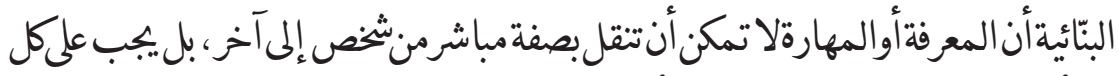

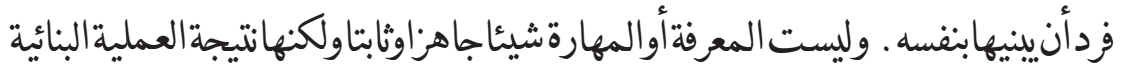

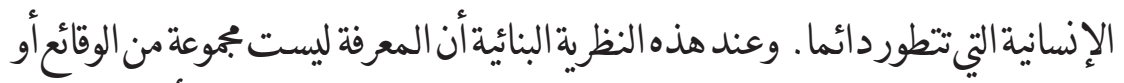

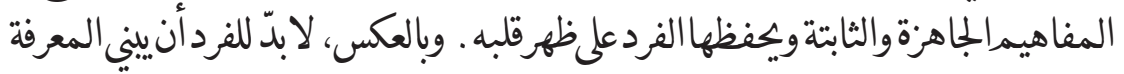

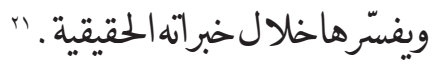

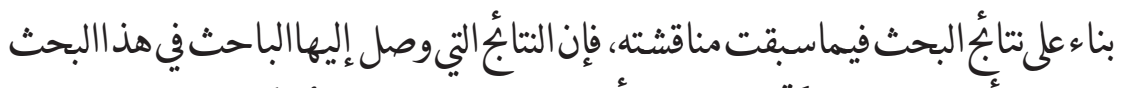

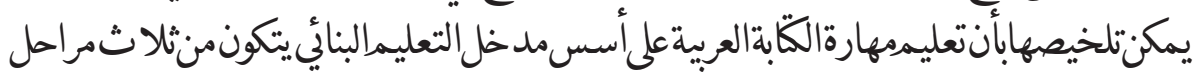

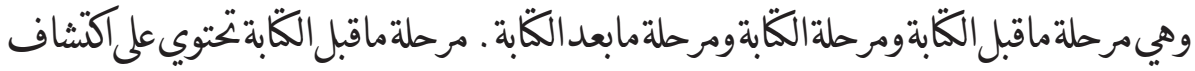

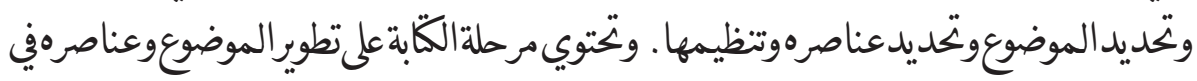

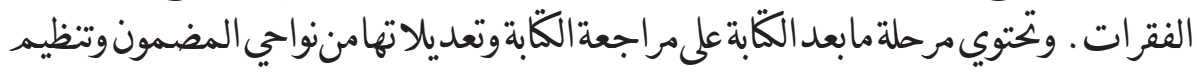

${ }^{20}$ Paul Suparno, Filsafat Konstruktivisme. h. 28.

${ }^{21}$ Nurhadi dkk., Pembelajaran Kontekstual., h. 33. 
الأفكار والمفردات والقواعد العربية والرسمالإملائي ـ. وتطبيقمدخل التعليمالبنائي في يستطيع أنيرقيمهارةالكّةبةالعربية.

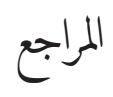

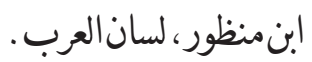

أحمدؤادمحودعليان، المهارات اللغوية ماهيتهازطرائتتد ريسها، الرياض:دار المسلم للنشروالتوزيع، $.199 r$

فتي علي يونس وآخرون، أساسيات تعليما للغة العربية والترية الدينية، القاهرة:دار الثقافة للطبعة

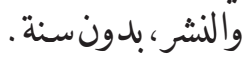

محمد علي الخولي، أساليبتدريس اللغة العربية، الرياض: مكتبة النهضة، ج19 19 .

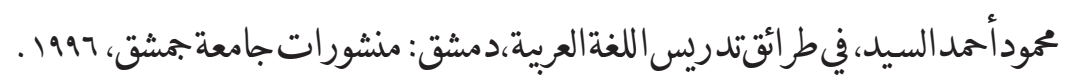

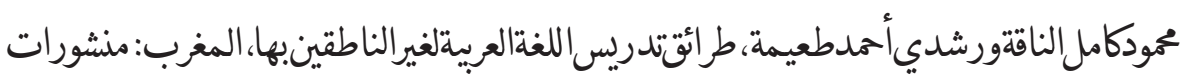

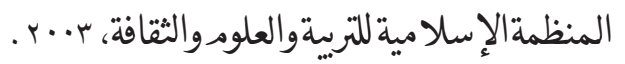

Cox, C., Teaching Language Arts, Boston: Allyn \& Bacon, 1999.

Nunan, David, Practical English Language Teaching, New York: McGraw Hill, 2003.

Nurhadi dkk., Pembelajaran Kontekstual dan Penerapannya dalam KBK, Malang: Universitas Negeri Malang Press, 2004.

Rochiati, Metode Penelitian Tindakan Kelas, Bandung: Remaja Rosdakarya, 2005.

Suparno, Paul, Filsafat Konstruktivisme dalam Pendidikan, Yogyakarta: Kanisius, 1997.

Syamsuddin A.R. \& Vismaia S. Damaianti. Metode Penelitian Pendidikan Bahasa, Bandung: Remaja Rosdakarya, 2006. 